\title{
Ler, escrever e publicar no mundo das ciências sociais
}

Eloísa Martín*

Resumo: O artigo apresenta as principais transformações da escrita acadêmica e das dinâmicas de publicação nas revistas científicas da atualidade. Revela alguns dos erros mais comuns no processo de redação, submissão e revisão, bem como oferece algumas soluções possíveis para encarar o processo de escrita, especialmente as primeiras ferramentas para a elaboração de um artigo acadêmico em ciências sociais. A partir de revisão bibliográfica e minha prática como professora de escrita acadêmica, ofereço algumas alternativas e sugestões para superar o medo da "folha em branco", organizar o tempo e entender o processo de escrita como uma atividade dialógica e coletiva, que requer tanto da leitura como de múltiplas reescritas.

Palavras-chave: Escrita acadêmica. Publicação acadêmica. Revistas científicas. Habilidades acadêmicas. Ensino da escrita

\section{Read, write, and publish in social sciences}

Abstract: This article presents the main transformations of academic writing and the current dynamics of publication in scientific journals. It reveals some of the most common errors in the writing, submission, and review process, and offers some possible solutions to deal with the writing process, especially the first tools for writing an academic article in Social Sciences. Departing from a bibliographical review and my practice as a professor of academic writing, I offer some alternatives and suggestions to overcome the fear of the "blank page", time administration, and understanding the writing process as a dialogic and collective activity, which requires both the reading as multiple rewriting.

Keywords: Academic writing. Academic publication. Academic journals. Academic skills. Teaching writing.

\section{Introdução}

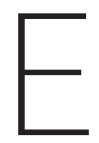

screver não é uma atividade natural e não é fácil. Não é fácil nem espontâneo para aqueles que fazem da escrita um afazer cotidiano (jornalistas, escritores) nem para os que têm na escrita uma de suas principais atividades, como os profissionais das ciências sociais e das humanidades. Para quem escreve eventualmente - pois sua profissão é de outra índole -, a escrita pode parecer uma missão impossível. Curiosamente, para quem está em processo formativo - seja na graduação ou na pós-graduação - a escrita chega a ser entendida

\author{
* Eloísa Martín é \\ professora associada \\ do Departamento \\ de Sociologia da \\ United Arab Emirates \\ University, United \\ Arab Emirates. \\ Orcid n. 0000- \\ 0003-4737-6032. \\ <eloisamartin@uaeu. \\ ac.ae>.
}


1. Refiro-me, aqui, a disciplinas obrigatórias oferecidas tanto na graduação como na pós-graduação nas universidades do Canadá e dos Estados Unidos, e aos laboratórios e retiros de escrita oferecidos a doutorandos e professores, organizados em universidades do Norte Global, que procuram não apenas ensinar a escrever, mas facilitam a experiência de escrita e o tempo necessário para tanto. Nas universidades brasileiras, alguns departamentos oferecem eventualmente minicursos e disciplinas optativas de escrita acadêmica, mas não há, até o momento, um treinamento contínuo de escrita, como parte da formação em ciências sociais. como um dom, isto é, uma habilidade natural ou inata que pode ser exercida espontaneamente, e que algumas pessoas possuem e outras, simplesmente, não. A diferença da maioria das universidades anglofalantes ${ }^{1}$ - de onde, ademais, se toma o exemplo do que "deve ser" um bom cientista, em termos de número e qualidade das publicações - nas universidades brasileiras, a escrita acadêmica não é uma disciplina obrigatória na grade, e são poucas a instituições que, mesmo nas humanidades, eventualmente oferecem cursos para ensinar a escrever. No entanto, nas mais diferentes atividades, mesmo aquelas profissionalizantes com ímpeto de intervenção ou as artísticas, escrever e publicar em periódicos científicos virou uma exigência cada vez recorrente.

Se a escrita é uma atividade complexa para qualquer pesquisador, para os pesquisadores iniciantes se torna inabordável. Parece haver um oceano intransponível até a publicação do primeiro artigo, por não saber como dar a primeira braçada para chegar lá. E para aqueles corajosos que se lançam na aventura sem saber muito bem o que fazer, geralmente o resultado é o morrer na praia da rejeição. A isso se soma a (falsa) ideia de que a escrita é um processo meramente individual, idiossincrático e de meditação íntima de quem escreve. Pelo contrário, mesmo precisando de momentos de isolamento e de reflexão individual, a escrita e a publicação precisam ser compreendidos como um processo não linear mas sistemático, coletivo e, em algum sentido, polifônico. As publicações não podem ser pensadas como o mero desovar dos resultado de pesquisa num veículo para sua disseminação, e muito menos como um simples índice da "produtividade" individual, mas como o resultado complexo de várias etapas e tomadas de decisão que envolvem esforços individuais e trabalho coletivo. Nesse sentido, e para além da coletividade evidente nos casos de coautoria ou pesquisa em equipe tal como mostrado no trabalho clássico de Knorr Cetina (2005), um trabalho publicado em uma revista acadêmica prestigiosa, necessariamente passou pela maioria (se não por todas) das seguintes etapas: comentários e críticas das versões preliminares, pareceres dos avaliadores e do editor da revista à qual foi submetida, revisão e ressubmissão para a mesma ou para outra revista acadêmica e, eventualmente, tradução e correção de provas. Tudo isso antes de entrar, oficialmente, no diálogo acadêmico da publicação.

O principal problema, no contexto da academia brasileira, radica na carência de treinamento específico na universidade (cursos, disciplinas e laboratórios oferecidos desde o início da graduação), na escassez de textos específicos em português (os poucos manuais sobre o assunto estão orientados por uma ideia de ciência e de comunicação científica originada nas áreas "duras" e pouco têm a ver com os processos epistêmicos e comunicativos das ciências sociais e das humanidades), e na combinação entre a falta de tempo e o grande número de alunos nas disciplinas 
regulares, o que impede aos professores o desenvolvimento de estratégias pedagógicas mais artesanais, ensinando o "ofício do sociólogo" - como diriam Bourdieu, Chamboredon e Passeron (1988) - no dia a dia da sala de aula.

Este breve artigo não tem a pretensão de resolver todas essas questões, mas indicar os primeiros passos na escrita científica: como escrever a primeira linha de um rascunho que, eventualmente, muitos meses depois, será a matéria-prima para escrever um artigo. Nos cursos de escrita acadêmica que tenho ministrado nos últimos dez anos, a maior dificuldade manifestada pelos alunos - da graduação até o doutorado - tem sido, precisamente, a enorme dificuldade para começar, para vencer a página (ou a tela) em branco. Mesmo os manuais que oferecem receitas (aparentemente) simples para escrever um artigo (Belcher 2009; 2010; Bursztyn et alii, 2010; Johnson \& Mullen, 2007; Becker \& Denicolo, 2012; Wallace \& Wray 2016, só para mencionar alguns) omitem os momentos prévios à preparação de um artigo, que nunca começa da página em branco, mas de rascunhos, relatórios de pesquisa, ou papers apresentados em conferências. Os alunos identificavam um gap - lido sempre como dificuldade individual - entre as próprias ideias e o passo a passo proposto por esses trabalhos, que dão por suposto que o artigo está, de alguma maneira, ora pronto na cabeça do autor, ora em versões preliminares já escritas. Mas, de fato, esse gap entre a "folha em branco" e o artigo publicado em uma revista científica envolve várias escritas prévias, numerosas discussões, releituras e revisões que, comumente, não são abordadas pelos manuais de escrita.

Nesse artigo, então, ofereço algumas alternativas e sugestões para superar esse gap de maneira consistente, bem como as primeiras ferramentas para a elaboração de um artigo acadêmico em ciências sociais. Antes de iniciar o planejamento para desenvolver o artigo, bem antes de preencher as lacunas de um artigo no formato Introduction - Method - Results - and - Discussion (IMRaD), antes de listar argumentos e montar a estrutura do texto, tem algum caminho pela frente. Esse trabaIho oferece, então, pistas para percorrer esse caminho e alguns marcos para não se perder no percurso até publicação.

\section{Para escrever, comece lendo}

Isso pode parecer contraproducente: afinal, você precisa mesmo escrever e cada minuto perdido longe do teclado o afasta da publicação de suas ideias e dos resultados de sua pesquisa. Ainda, se você está naquele momento em que realmente precisa e deve publicar algum trabalho logo, para se candidatar a uma pós-graduação, a uma bolsa ou a um emprego, "perder tempo" é a última coisa que você quer. A pressão 
pela publicação se torna ainda mais dramática quando consideramos que cada vez mais cedo se exige dos estudantes contar com publicações, sem necessariamente oferecer os recursos para que elas sejam factíveis e de uma qualidade aceitável.

Para pesquisadores iniciantes e sêniores, hoje em dia, publicar é o principal índice de "produtividade" intelectual, de avaliação de metas e de prestígio acadêmico (ver Vanderstraeten, 2010; Strathern 1997; 2000; Hanafi, 2011; Martín 2016b). Para colaborar nesse processo de formar pesquisadores produtivos, dúzias de páginas de manuais de escrita e posts na internet afirmam que é indispensável escrever todos os dias, ensinam como fazê-lo e orientam sobre como administrar o tempo para sermos mais produtivos: Wendy Belcher (2009), por exemplo, propõe um período de 12 semanas para produzir um artigo e Joan Bolker (1998) aposta que apenas 15 minutos a cada dia farão com que você finalize sua tese de doutorado a tempo.

No entanto, é necessário lembrar que a publicação acadêmica não é - e não deveria ser - apenas a "desova" de resultados de pesquisa para engordar o Currículo Lattes. Idealmente, enquanto cientistas, escrevemos e publicamos para fazer parte de uma "conversa em andamento" com outros pesquisadores (Grauerholz, 1999: 312). Essa conversa está registrada nas publicações prévias e a única maneira de entrar no diálogo é conhecer o estado da arte do assunto no qual você quer intervir. A revisão bibliográfica exigida para qualquer texto acadêmico (desde o TCC até à tese de doutorado, passando pelas apresentações em congressos, artigos e até resenhas de livros) é uma exigência indispensável para que todos os envolvidos "falem a mesma língua", isto é, compartilhem uma base comum de entendimento. Não apenas porque - como aponta Becker (1986) - ninguém vai se interessar nos resultados de sua pesquisa se você não propuser algum tipo de relação com o que os outros têm feito e divulgado, mas porque é justamente a partir do conhecimento do que os outros fizeram que é possível realizar uma pesquisa (e portanto, escrever um artigo) original e relevante, isto é, que dialogue, colabore e faça um aporte ao processo mais amplo de fazer ciência. Voltaremos sobre esse assunto na sequência.

A leitura não se limita apenas a estar atualizado sobre o debate do próprio campo de pesquisa. Se o objetivo é publicar, e de acordo com a afirmação de Cassani (2011: 63ss), para escrever não basta apenas ler, é indispensável ler como escritor, de maneira de entender as características próprias do código - que inclui as regras ortográficas, as convenções gramaticais, a estrutura e o registro de cada tipo textual. Falar a mesma língua, aqui, inclui o estilo e a retórica, pois mesmo dentro da escrita científica existem modos (e modas!) específicos para se comunicar em 
cada espaço específico: a escrita é diferente para um pôster, um paper, um artigo, um capítulo de livro, ou um texto monográfico. Em termos mais específicos e visando à escrita do um artigo acadêmico, ler é fundamental por três motivos principais:

1. para estar atualizado em termos da literatura recente sobre o tema de pesquisa abordado, de maneira que a contribuição seja original e relevante;

2. para aprender o estilo específico da publicação científica; e

3. para conhecer as revistas onde, eventualmente, o trabalho será publicado: seus objetivos, o estilo peculiar, suas normas de publicação, o tipo de artigo que publicam em geral e nas diversas subseções.

Como cientistas sociais, lemos mais - muito mais - do que escrevemos. E mesmo nunca tendo escrito um artigo antes, o cientista iniciante possui alguns conhecimentos implícitos sobre o que é a boa escrita. É só pensar no que se tem lido, tanto por trabalho como por lazer, e identificar as características daquilo que se achou prazeroso e útil ler. Em geral, uma escrita fluida, clara, organizada, com uma ideia bem desenvolvida e bem estruturada (com começo, meio e fim), sem redundâncias nem linguagem escura é sempre parte de uma boa experiência de leitura. Curiosamente, para o senso comum - incluindo o senso comum "acadêmico"- pareceria que um texto obscuro, complicado, difícil de ler é "melhor", pois não seria acessível para qualquer leitor leigo. No entanto, não é um uso excessivo do jargão, o uso pobre da gramática ou as construções retóricas mirabolantes o que diferencia o leitor leigo do iniciado, mas o conhecimento dos conceitos e das teorias que embasam a ideia que está sendo desenvolvida no texto.

Eis o primeiro grande mito da escrita acadêmica que precisa ser desmascarado: "um texto difícil de ler é um texto sofisticado". Um texto teórica ou conceitualmente sofisticado desafia nossos pressupostos, nos faz pensar, gera incomodidade e, em alguns casos, até revolta. Mas a dificuldade não está - e não deve estar - na escrita, mas nas ideias: afinal, o conhecimento científico se constrói por adição e, em alguns casos, por contradição com os conhecimentos anteriores. A peculiaridade da escrita científica ou acadêmica radica, assim, em estar baseada em uma pesquisa prévia, portanto o autor parte do pressuposto de que seus leitores, colegas cientistas, conhecem a maioria das premissas teóricas, lógicas e metodológicas que embasam o argumento, isto é, uma linguagem e um entendimento comum que não é partilhado pelos leigos. Portanto, um texto se torna difícil de ler porque está mal escrito e não por ser sofisticado. Apenas está mal escrito. 
A escrita científica, quiçá mais do que qualquer outra, é fundamentalmente comunicação: trata-se de passar as ideias para outrem, de fundamentar as afirmações realizadas no texto, teórica ou empiricamente, de maneira de mostrar aos leitores a solidez do argumento. Se a ideia não é corretamente comunicada, se for comunicada de maneira pobre e parcial, ela não será compreendida no seu potencial e, geralmente, será desestimada, pois ninguém tem paciência para desentranhar a ideia que o próprio autor não soube desenvolver com clareza.

A estrutura de um artigo - como a de um conto (ver Cortázar, 2013: 29-32) - é intencional, fechada, e requer, por motivos técnicos (o limite de palavras e o estilo comunicativo, basicamente) ser bem pensada. O autor de um bom artigo, como o de um bom conto, irá apresentando os personagens, as ações, os desfechos sempre aos poucos, mas em momentos bem pensados. Algumas informações que são lógica ou cronologicamente anteriores, sem as quais os elementos que virão depois não poderão ser compreendidos, serão apresentadas primeiro. Mas essa organização acontece durante as várias reescritas, de modo a outorgar uma ordem, uma organização e uma dinâmica internas. Por exemplo: comecei essa seção afirmando que para escrever é fundamental ler e, na continuação, mencionei três motivos que sustentam essa afirmação. Na sequência, aponto conexões entre escrita e leitura, de modo de sensibilizar o leitor para o meu argumento. Assim, ao iniciar a seção, o leitor é informado logo sobre a ideia principal e os argumentos que, subordinados, sustentam essa afirmação. Portanto, para demonstrar meu ponto, organizo lógica e retoricamente meu texto de maneira a sustentar meu argumento, fornecendo recursos teóricos, metodológicos e empíricos para tanto. Alternativamente, poderia ter começado simplesmente afirmando que a escrita não é uma atividade natural, indo seguidamente a dar exemplos para, no meio do texto, "lembrar" a minha ideia principal, que é sublinhar a importância da leitura para a escrita. Ainda que todos os argumentos sejam exatamente os mesmos, a ideia principal "perdida" no meio do texto e os argumentos subsidiários desordenados (ou confundidos com a ideia principal, por exemplo), fariam com que a leitura fosse mais cortada e que, ulteriormente, o argumento principal que procurava desenvolver, ficasse encoberto.

Para aprender a escrever, então, comece lendo. E observe, naqueles artigos que você achou mais úteis e mais bem escritos, como foram estruturados. Examine a organização do texto, a divisão em seções e subseções para tentar entender como o autor pensou o fluxo do argumento. Um exercício muito útil para isso é copiar os subtítulos e as principais ideias de cada seção em um papel: isso torna visível tanto a estrutura argumental quanto a elaboração lógica do argumento. Assim, então, ler também é escrever. 


\section{Escrever é, sempre, reescrever}

A primeira versão de um artigo não é nunca aquilo que será enviado para publicação, muito menos o que será finalmente publicado. O processo de publicação exige várias escritas e edições antes de ser aceitável para submissão e aprovado para publicação. Para o cientista iniciante, sobretudo para aqueles que estão ainda na graduação e acostumados a preparar trabalhos finais de véspera, a disciplina (no sentido do exercício rotineiro, organizado e contínuo) que a escrita requer pode afigurar-se desestimulante, em um primeiro momento: a correção infindável, a revisão contínua, a sensação de que "nunca está bom o suficiente", a descoberta de que não escrevemos tão bem quanto achávamos. Porém, é apenas na perseverança das múltiplas escritas que as habilidades são aprendidas, treinadas e aperfeiçoadas.

Portanto, pratique o desapego e relacione-se com seu texto como uma obra (praticamente) sempre inacabada, e reescreva-o. Os melhores escritores sempre corrigiram e editaram seus textos, então, por que os seus (e os meus!) trabalhos escritos não precisariam?

A seguir, gostaria de identificar oito diferentes momentos da escrita, que são, na verdade oito momentos de reescrita.

\section{Escrita como autorreflexão}

É a primeira tentativa de colocar os pensamentos em palavras, objetivar e organizar as observações e as análises da pesquisa que estão "na cabeça". É uma escrita quase narcisista: apenas para nós mesmos, para registrar as reflexões e, mais importante, para ajudar a pensar. Nesse sentido, e quem já tem experiência de escrita irá reconhecer isso com clareza, algumas ideias só irão aparecer na hora de escrever, no momento exato em que estamos digitando no computador ou rascunhando à mão no nosso bloco de notas. Essas ideias precisarão ser refinadas e sopesadas em função dos resultados de pesquisa, dos diálogos com a literatura prévia e reescritos repetidamente até estarem prontos para serem comunicados e, posteriormente, publicados.

É importante lembrar que nem tudo o que se escreve nessa primeira etapa irá servir para uma publicação. Alguns - muitos, até - dos parágrafos escritos serão muito confusos, redundantes, sem sentido ou estarão completamente equivocados. Mas é indispensável escrever todos eles - sim, até mesmo os trechos incorretos - como parte desse exercício de colocar as reflexões em palavras. 


\section{Escrita dos resultados da pesquisa}

Um artigo acadêmico não é a somatória de ideias soltas, opiniões ou observações impressionistas juntadas em um texto, é o resultado de uma investigação em diálogo com a bibliografia prévia sobre o assunto. A pesquisa sobre a qual vou escrever meu artigo pode ser empírica ou bibliográfica, portanto sempre haverá uma pergunta, um objeto, um universo e uma metodologia que podem ser objetivamente identificáveis pelo leitor.

Neste segundo momento, a escrita é mais objetiva para permitir a organização em grande escala dos resultados da pesquisa em andamento. O formato de relatório permite que um leitor iniciado possa compreender os passos da investigação, as ferramentas utilizadas e entender como se alcançaram os resultados. Nesta etapa não há, necessariamente, uma discussão desses resultados à luz da literatura do tema, ainda que o conteúdo analítico esteja dado pelo recorte e pela seleção dos dados que serão examinados nesse momento.

\section{Escrita para comunicação}

É o primeiro esforço de contar para alguém os resultados da pesquisa e as reflexões e análises que começamos a construir sobre eles. Nossos primeiros leitores serão nossos professores e nossos colegas mais próximos, aqueles que participam da mesma equipe de pesquisa ou do mesmo grupo de leituras. Um texto preparado para a primeira comunicação surge dos passos anteriores: a escrita como autorreflexão e organização dos dados de pesquisa. No momento de comunicar, é indispensável começar a integrar a bibliografia prévia sobre o assunto que estamos investigando, para - mesmo sem ter uma completa clareza sobre a estrutura do texto - minimamente orientar os nossos leitores sobre o escopo de nosso texto ou, pelo menos, para onde esse esforço não está sendo dirigido. A bibliografia, então, funcionará aqui tanto como mapa, quanto como linguagem comum para que os leitores possam compreender os conceitos que começarão a aparecer no texto. Nessa etapa, é fundamental contar com a leitura crítica dos colegas - dos quais se espera a mais rigorosa e incisiva das críticas. No mundo acadêmico, o melhor amigo não é aquele que elogia o tempo inteiro ou nunca faz uma crítica contundente, mas aquele que é capaz de assinalar tanto os pontos fortes do texto, aí onde você deve investir e sublinhar, quanto de ser feroz em relação aos pontos fracos, assinalando até erros de gramática, se necessário for. O melhor amigo acadêmico é aquele que, ao observar que o texto está confuso, a bibliografia fraca ou a metodologia inconsistente, não deixa você sair com esse material a público sem antes retificar as insuficiências detectadas. 


\section{Escrita para a primeira publicação}

A primeira vez que o texto sai do círculo mais próximo de leitores não precisa ser logo em forma de artigo. De fato, o ideal é que a estreia, a primeira vez que fazemos públicas as nossas ideias, não seja como um manuscrito para revista científica, mas em forma de comunicação ou pôster para um congresso, uma entrada num blog ou um artigo breve para um newsletter. Algumas universidades e centros de pesquisa produzem coleções - geralmente on-line - de working papers (trabalhos em andamento) tanto para seus estudantes como para os próprios professores, o que é também um excelente veículo para testar as ideias e receber algum feedback.

Nesse momento, para preparar essa primeiríssima publicação, é necessário aprender a recortar. Numa investigação qualquer, o pesquisador vai lidar com diferentes níveis de análise, com diversos desdobramentos possíveis de seu material de pesquisa. E, para elaborar a apresentação ou o pôster, será indispensável restringir o foco a uma única ideia, um único ponto focal que servirá como recorte do argumento para esse texto específico.

Imagine sua pesquisa como um livro com capítulos que precisam ser inteligíveis individualmente. Mesmo tratando-se de um empreendimento mais amplo e abrangente, as ideias precisam ter um espaço específico para serem desenvolvidas adequadamente: o romancista - como o pesquisador - não pode simplesmente lançar tudo de uma só vez, sem ordem ou coerência. O autor apresenta as ideias, os argumentos e os personagens subordinados (mas, ainda assim, fundamentais para contar a história como um todo) de maneira organizada e separadamente. O pesquisador começará escolhendo uma parte da sua pesquisa (um nível de análise, um evento, uma dimensão específica) para desenvolver seu paper.

Nesse primeiro momento de fazer-público ainda não é necessário ter todas as questões teóricas ou analíticas resolvidas. Como "trabalho em andamento" ou comunicação em congresso, espera-se - e é desejável - uma contribuição ainda não completamente fechada, e isso é um bom sinal para os leitores ou a audiência, que poderão discutir, contra-argumentar e sugerir modificações ao autor. O leitor ou a audiência no congresso poderá avaliar se os argumentos se sustentam - a partir de referências à bibliografia, aos dados, aos exemplos -, apontar pontos cegos, referências bibliográficas ignoradas que poderiam ampliar ou contestar o argumento, assinalar a necessidade de exemplos ou de novos dados para respaldar as afirmações.

Esse é um excelente momento para receber sugestões e críticas, que serão fundamentais para aprimorar o trabalho nas escritas subsequentes. Se o argumento 
2. Um juízo simplório à revisão de pares nas ciências sociais é acreditar que, apenas por não concordar com o denominado "marco teórico", um parecerista poderia rejeitar um artigo. Ainda que de fato isso às vezes possa acontecer, uma boa revisão de pares observa a relevância, a originalidade e a construção lógica do argumento, validando a partir desses critérios sua pertinência científica. Para uma análise mais compreensiva da revisão de pares em revistas acadêmicas, ver Martín (2016a).

3. Essa seção está baseada no meu artigo (Martín, 2014), ao qual remeto o leitor para maiores detalhes. estiver logicamente bem construído, se a arquitetura do artigo for consistente, as críticas idealmente não serão uma questão de opinião ou de perspectiva teórica ou metodológica, e não invalidarão meu trabalho². Ao contrário: essas avaliações negativas não devem ser tomadas como motivo de frustração, pois é apenas através delas que podemos corrigir os erros, melhorar os pontos fracos e reforçar os pontos fortes que, talvez, ainda não estejam claramente definidos.

\section{Escrita para edição e aprimoramento das ideias}

Os working papers, as comunicações em congressos ou os posts em blogs certamente receberão comentários dos colegas, dos professores ou ainda do público em geral. Considere as críticas e sugestões, avalie sua pertinência (com a ajuda de seu professor, se tiver dúvidas) e revise seu trabalho. Inclua as sugestões bibliográficas, reescreva os parágrafos que a audiência considerou obscuros, contextualize dados que para você são óbvios, mas não necessariamente para seus leitores. E depois de ter feito isso, deixe descansar uns dias. Pode ter certeza que, reencontrar o texto após um breve tempo (não menos de um dia, não mais de uma semana), você será capaz de reler com novos olhos, encontrar erros que antes não tinha visto, reescrever parágrafos com maior clareza e, ainda, orgulhar-se das frases bem escritas e do progresso de sua pesquisa.

\section{Escrita para submissão para uma revista ${ }^{3}$}

Agora que você já tem avançado na sua escrita, melhorado seu texto, recebido feedbacks de colegas e professores, chegou a hora de publicar em uma revista científica. Beneficiado pelas críticas prévias e o trabalho de edição, seu texto tem mais chances de ser bem recebido e publicado. Mas, atenção! Não qualquer texto pode ser publicado em qualquer revista. Não existe algo assim como "um bom artigo" que poderia ser publicado em qualquer lugar. Isso porque um bom artigo não é definido somente por seu conteúdo, mas especificamente por uma escrita adequada ao periódico em questão. Portanto, você precisa produzir um trabalho específico para uma revista específica - e para conhecer as revistas, como explicava acima, é necessário conhecê-las lendo-as!

A escolha da revista pode estar baseada em uma variedade de motivos, que irão da classificação nos índices relevantes para a academia nacional, até sua trajetória num campo de debates específico ou a proximidade do autor com os editores. Mas, para além dessas motivações, a escolha da revista é fundamental pois onde publicar irá definir o que publicar e como publicar seus resultados de pesquisa. As revistas - mesmo as da mesma área disciplinar - possuem diversos perfis editoriais e es- 
tão dirigidas a públicos diferentes, portanto exigirão adequações dos manuscritos destinadas ao amoldamento do texto no perfil do periódico e seja relevante para seus leitores. Nesse sentido, é indispensável entender que as revistas não são um espaço para "desovar artigos", mas arenas de debate e, como apresentei acima, é indispensável que o manuscrito se adapte a esse espaço comum, a essa linguagem compartilhada, que embasa o diálogo entre autor e leitores.

Um mesmo working paper pode ser preparado para diferentes revistas, e isso vai exigir estratégias específicas para as diversas publicações. Na sequência assinalarei as três principais características de uma revista que o jovem investigador deve considerar quando for preparar o seu manuscrito para submissão.

Primeiro, considere a o eixo geográfico ou idiomático da revista escolhida e decida se ela é uma revista nacional, regional ou internacional. Em alguns casos, o foco geográfico aparece logo no nome da revista, quando se referem explicitamente aos estudos europeus, sul-asiáticos, latino-americanos ou africanos. Mas, em muitos casos, o título da publicação não informa seu campo de interesse ou pode até ser enganoso: quase todos os países possuem uma revista nacional chamada "Sociologia", "Sociologias" ou "Estudos Sociológicos", o que poderia fazer você pensar que essas são revistas de temáticas abertas e foco geográfico amplo, quando, na verdade, estão focadas principalmente no desenvolvimento de debates domésticos. O escopo geográfico diz sobre o grau de contextualização que é indispensável imprimir no texto para que seja compreendido pelos leitores: numa revista nacional, alguns assuntos e personagens não precisam ser apresentados, mas o mesmo caso, para uma revista internacional, deverá ser devidamente contextualizado.

Segundo, vá para os objetivos e o escopo da revista, e descubra que tipo de artigo essa revista está interessada em publicar. Existem revistas generalistas que publicam uma ampla variedade de questões relacionadas a uma disciplina em particular (sociologia, antropologia, ciências políticas) e também há as revistas especializadas, que definem seu conteúdo em função de determinadas áreas, subáreas (religião, música, política, estudos rurais), discussões teóricas (revistas de estudos marxistas ou simmelianos) ou contextos geográficos (os chamados estudos de área) e, ainda, algumas podem ser multidisciplinares. Para revistas generalistas, você deve manter seu artigo mais aberto e livre dos jargões que você empregaria em uma revista especializada no seu tema de pesquisa. Para revistas mais específicas, você pode considerar como parte do acervo comum os jargões e os debates próprios do campo.

Por último, mas não menos importante: o formato do artigo. Podemos encontrar dois principais estilos em revistas acadêmicas. O estilo IMRaD é o mais ensina- 
4. Vários autores têm descrito o modelo IMRaD e como "preencher" cada uma das seções. Ver, por exemplo, Slafer (2009), Bursztyn, Drummond e Nascimento (2010), Hartleyk (2012), Branson (2004), dentre muitos outros. do em livros sobre redação científica e tem se tornado o modelo hegemônico de publicação científica, pelo menos a partir dos anos 1970 (Solaci \& Pereira, 2004). Considerado o único formato possível para as ciências "duras", é adotado crescentemente nas publicações das ciências sociais em inglês, especialmente nos Estado Unidos. Os artigos IMRaD são estruturados em "Introdução", "Métodos", "Resultados" e "Discussão" ${ }^{4}$. A grande vantagem desse modelo, é que facilita tanto a leitura de resultados de pesquisa - conforme aponta Hartleyk (2012) -, quanto argumentos que não precisam de uma construção retórica mais complexa para fazerem sentido. Assim, em lugar de precisar seguir linearmente a totalidade dos conteúdos do texto, os leitores podem ir diretamente nas seções específicas que fornecerão as informações que estão procurando. A estrutura fixa e de conteúdos preestabelecidos em cada uma das seções facilita tanto a escrita como a leitura e posterior citação do artigo.

No entanto, nas ciências sociais, muitas vezes esse modelo resulta demasiadamente esquemático e limitador. Pesquisas de cunho qualitativo ou de revisão bibliográfica nem sempre se adaptam a esse modelo, pois precisam de uma estrutura mais flexível para desenvolver os argumentos. Temos então o modelo narrativo, que resulta mais adequado para análises qualitativas e para o desenvolvimento de discussões teóricas e conceituais. O estilo narrativo estruturado em três partes principais - "Introdução", "Corpo do texto" e "Conclusão" - permite que o "Corpo do texto" seja dividido em capítulos ou seções, de maneira a melhor organizar o argumento, além de ajudar ao leitor a acompanhar o fluxo de suas ideias.

\section{Escrita nas revisões durante o processo de avaliação}

A escrita de um artigo científico não termina quando você o envia para a revista. As revistas científicas decidem o que será ou não publicado com base no parecer duplo cego. Isto é, em geral, pelo menos dois pareceristas (especialistas no assunto do artigo) avaliarão o trabalho e recomendarão ao corpo editorial se o artigo está apto para ser publicado e farão sugestões para o aprimoramento do artigo. O processo é completamente anônimo, para garantir a objetividade e a lisura: nem os pareceristas sabem quem é o autor, nem o autor saberá quem foram seus pareceristas - por isso se denomina "duplo cego". Em suas avaliações os pareceristas farão diversas recomendações para que autor possa melhorar seu artigo e enviar uma nova versão para o editor. Esse processo pode se repetir várias vezes (em geral duas ou três) até que os pareceristas e o editor estejam contemplados com as demandas de correção do artigo. 


\section{Escrita após a rejeição}

Em determinadas ocasiões, os pareceristas consideram que o artigo não cumpre os requisitos mínimos de publicabilidade ou precisa de mais tempo de trabalho e maturação (ver Martín, 2016a). Nesses casos, os editores costumam rejeitar o artigo. A rejeição de artigo é cada vez mais normal, pois as revistas recebem um número cada vez maior de submissões e os autores têm cada vez menos tempo para se dedicar a preparar um bom texto. Ter um artigo rejeitado nunca é uma experiência agradável, mas é absolutamente normal: quanto mais você submete para publicação, mesmo sendo um pesquisador renomado, estatisticamente falando, mais chances tem de ter um artigo rejeitado. Pesquisas internacionais mostram que quase todos os pesquisadores têm a experiência de trabalho rejeitado alguma vez - entre 85 e $90 \%$ de autores proeminentes admitem ter passado pela experiência (Gans \& Shepherd, 1994). E provavelmente os 10 a 15\% restantes podem não querer admiti-lo, ou não estão enviando suficientes manuscritos para publicação. Acredite: mesmo aqueles grandes nomes mundialmente reconhecidos, já tiveram artigos rejeitados - e não necessariamente no início da carreira.

Pelo menos estatisticamente, se você encaminha um artigo para uma revista internacional de alto perfil (algumas das revistas, mas não todas, indexadas como Qualis A1 estão nesse estrato) você terá uma chance de entre 30\% (no melhor dos casos) e $5 \%$ (em revistas altamente competitivas, como Nature ou Science) de ser aprovado. Nas revistas brasileiras, as probabilidades são mais amáveis, mas ainda você vai enfrentar um 20 a 50\% de chance de rejeição, dependendo do periódico.

Assim, se a rejeição é a norma, não se trata, a princípio, de um problema pessoal ou idiossincrático.

Ter um artigo rejeitado nunca é uma experiência agradável, mas ademais de normal, não é o fim do caminho. O destino de um artigo rejeitado não precisa ser a lixeira. Em lugar de considerá-la como um fracasso, a rejeição precisa ser entendida como parte desse processo de múltiplas escritas. Uma pesquisa recente mostra que os artigos rejeitados, se apropriadamente revisados e retrabalhados, têm maiores chances de serem publicados em uma segunda ou terceira submissão e, ainda, em uma revista com um índice de facto de maior impacto (ver Calcagno et alii, 2012).

Os artigos rejeitados, se melhorados seguindo as orientações dos pareceristas, têm maiores chances de serem aceitos para publicação no futuro próximo, em revistas ainda mais prestigiosas que aquela que rejeitou a primeira versão. Artigos rejeitados mais de uma vez, após o trabalho de revisão e edição podem até ser publicados em 
revistas que estão no topo do prestígio científico. Então, mesmo que rejeitado, a escrita do artigo só cessa quando ele for publicado. Mas, atenção! Releia o parágrafo acima e preste atenção às palavras-chave marcadas em itálicas: a (re)escrita contínua é a chave do sucesso. Nunca reapresente um artigo rejeitado sem revisá-lo, mesmo que seja para uma revista de menor prestígio: o mundo acadêmico é bem pequeno e existem grandes chances de que o mesmo parecerista receba seu artigo novamente. Se ele não foi melhorado, você já pode adivinhar o resultado dessa nova tentativa.

Na hora de revisar o seu artigo, não deixe que os comentários negativos - e em alguns casos, até grosseiros - dos pareceristas o desestimulem. Após o impacto de receber a carta do editor comunicando a rejeição, deixe dormir o texto um ou dois dias, e depois retome a tarefa. Não demore mais do que isso antes de retornar à escrita. Corrija os erros, reorganize o texto, reavalie e considere com atenção aqueles pontos nos quais os pareceristas concordaram, e corrija o texto. Por incrível que pareça, é bem possível que você acabe concordando com os pareceristas na sua versão final. Quando pronto, reapresente-o.

\section{Não tenho tempo para escrever!}

Esse parece ser o maior problema para quem precisa escrever e publicar. De fato, sempre estamos urgidos por outras demandas de nossa profissão. Mesmo para os professores-pesquisadores, sempre há aulas para preparar, bibliografia que revisar, alunos que supervisar, dúzias de atividades administrativas, viagens e exigências da pesquisa que fazem com que a escrita seja deixada "para outro momento"... que nunca chega. A procrastinação na academia, como mostra Somers (2008), é um fenômeno muito recorrente (chegando a $70 \%$ entre os estudantes universitários nos Estados Unidos) e pode ser atribuído a várias causas, mas sempre oferece um mesmo resultado: poucas ou nenhuma publicação para con(s)tar.

Como anunciei no começo deste texto, escrever não é um ato natural e espontâneo. É, ademais, uma atividade que gera muita angústia e frustração: aquelas ideias que, em nossa cabeça, aparecem com uma clareza diáfana, na hora de serem colocadas em palavras, fogem ou já não aparecem tão claras, e nos damos conta que nem estavam tão bem organizadas e que existe uma dúzia de pressupostos que precisamos esclarecer para que nosso argumento faça sentido. Por isso, não escrever é sempre tão tentador. Na dúvida, é sempre melhor ficar com a sensação de termos uma ideia genial na cabeça que tentar comunicá-la e nos darmos conta que nem era tão genial ou - pior ainda! - que para alcançar seu zênite precisa de muito - muito - trabalho. 
Ninguém tem tempo para escrever, escrever não é nunca uma urgência e não se resolve rapidamente. Portanto, precisamos criar o tempo para escrever. Mesmo aquelas pessoas muito ocupadas, com demandas de trabalho, afetivas ou domésticas, podem criar o tempo para escrever. Enumero algumas sugestões que poderão ajudar nesse processo.

\section{Organização e planificação é fundamental}

Em primeiro lugar, faça um horário de atividades. A depender do tipo de texto que tenha de escrever (um artigo original, uma revisão, uma tese), planifique os próximos dias, semanas ou meses. Inclua e classifique as atividades indispensáveis (as aulas, os horários de escritório ou de trabalho normal, mas também o tempo destinado às obrigações familiares e domésticas), as atividades importantes (estudar, encontros com a família e os amigos, e todas as atividades regulares que você realiza: religiosas, esportivas, de voluntariado, artísticas) e as atividades eventuais inadiáveis (provas, aniversários, prazos que deve cumprir, consultas médicas, viagens marcadas). Você vai completar muitos dos horários nesses dias, mas também vai descobrir que há um número de horários que você habitualmente usa para atividades de diversa índole: de entretenimento, domésticas, de descanso etc., mas, especialmente, muito tempo perdido. Calcule quantas horas de programas de TV você assiste, que nem gosta tanto. Ou o tempo que você investe nas discussões infindáveis no Facebook sobre os assuntos supérfluos e esquecíveis: você lembra a grande discussão que tomou três longos dias mês passado, que fez que ficasse discutindo até às três da manhã com um desconhecido? Ninguém lembra. Os enormes textos no Facebook são efêmeros, os artigos são para sempre.

Perante as múltiplas demandas e distrações, então, é indispensável começar a priorizar. O tempo da escrita é um tempo seu, para o desenvolvimento de suas ideias, para o progresso de sua carreira: é um tempo individual, íntimo, e muito necessário. Então, observe novamente o seu horário de atividades e avalie quando você poderia dedicar seu tempo para a escrita, cortando atividades que não são imprescindíveis e sobretudo aquelas nas quais você nem trabalha nem descansa. No curto prazo, você até pode suspender temporariamente atividades consideradas indispensáveis e importantes - e mesmo algumas inadiáveis, como viajar para o casamento de um primo, quando você perdeu todas as prorrogações para entregar a tese. Mas como escrever vai ser parte da sua vida (se você decidir pela carreira de pesquisador) será preciso conciliar todas as atividades de sua existência e incluir a escrita, dependendo do momento, nas atividades indispensáveis, importantes ou inadiáveis, junto com as demais. 
Saiba que a escrita sempre precisa de um tempo de "preaquecimento" antes de começar a fluir e que um par de páginas pode exigir várias horas de trabalho ininterrupto. Encontre faixas entre duas ou três horas, pelo menos duas vezes por semana, e designe esse tempo apenas para escrever. Mas lembre-se:

1. escrever é sempre trabalhoso e cansativo e você irá achar muito mais divertido fazer outras coisas (incluindo aquelas que normalmente você odeia fazer, como organizar gavetas ou ligar para aquela tia distante); e

2. sempre haverá outras demandas, outras vontades e urgências aparecendo; não sucumba às primeiras e, no caso das últimas, se forem realmente imperiosas, suspenda outras atividades para atendê-las, nunca a escrita.

Em um ponto, escrever é como ser maratonista: precisa treinamento e perseverança. Você não vai conseguir correr cinco quilômetros na primeira tentativa, mas vai precisar correr, todos os dias um pouco, para depois conseguir ter fôlego (e vontade!) para corridas de mais longo alcance.

Não desespere, mas não desista.

\section{Organize a escrita}

Faça um roteiro dos tópicos a desenvolver e liste tudo o que precisa ser incluído para que os argumentos façam sentido: discussões sobre determinados conceitos, apresentação dos dados (que podem precisar ser retrabalhados), as leituras que foram recomendadas e que precisam ser incluídas, a tradução de determinado parágrafo, o tratamento digital de alguma foto que queira incluir etc. Caso esteja fazendo a lista no seu computador, imprima-a e identifique tarefas com cores ou qualquer sinalização pessoal para marcar a importância da tarefa e coloque num lugar visível. Nesse momento, a visualização é indispensável por dois motivos:

1. para observar e analisar o roteiro, comprovar se as ideias fazem sentido entre si, se os nexos que relacionam umas às outras são logicamente conectados, se tem alguma ideia que parece estar sobrando;

2. ao desgranar o artigo em várias atividades pequenas e limitadas, suas duas horas de trabalho diárias irão ser suficientes para concluir pelo menos uma tarefa, o que dará uma sensação de progresso do trabalho - indispensável para não desistir do esforço. 


\section{Estabeleça metas realistas}

Começar um artigo hoje e se propor "acabar o artigo até amanhã" não é uma meta e certamente não é realista, enquanto são muitas as atividades que precisamos realizar e, mesmo que tenhamos 24 horas por dia aparentemente "livres" para escrever, sabemos que há outras atividades e distrações na espreita. Para algumas pessoas, serve colocar um limite de palavras a ser completado diariamente. Outros preferem marcar tempos, até utilizando um timer (a popular técnica pomodoro). Outros optam pelas listas de tarefas: resolver questões do argumento, organizar os dados ou a bibliografia, que serão riscado à medida que são resolvidos, dando essa importante visão do progresso do trabalho. Outros ainda funcionam com prazos: dois dias para resolver a seção de "Discussão" ou uma tarde pra revisar a "Bibliografia". Uma combinação das diferentes formas de organizar as tarefas pode resultar, se estamos tratando com um projeto de longo prazo, como a preparação da primeira versão de um artigo ou de uma tese de doutorado.

\section{Faça listas e elabore uma agenda}

O melhor da lista é poder observar o avanço de maneira clara e objetiva. O pânico da tela em branco se resolve quando vamos, aos poucos, finalizando as pequenas tarefas que fazem ao texto final. Mas, em geral, autores iniciantes - ou nem tanto costumam imaginar que o tempo é flexível, sobretudo quando se tem um mês para revisar o artigo ou os próximos dois anos para escrever a tese ou dissertação. Pelo contrário, a escrita requer múltiplas pequenas atividades feitas ao longo desse tempo todo, rotineiramente. Roma não se fez em um dia e, certamente, não é possível acabar um artigo começando na véspera do prazo final.

Na hora de elaborar a lista, o importante não é apenas o registro das tarefas a serem realizadas, mas a planificação. Para algumas pessoas, uma lista de coisas para fazer (check list), pode ser suficiente. Para outros, sobretudo se a lista é longa e bem especificada, pode ser simplesmente desestimulante. Agendar as tarefas, nesse caso, é uma boa solução. Belcher (2010) oferece algumas alternativas úteis para organizar o esforço maior de encarar a escrita de um artigo. Mas listar as atividades e separar tempo específico num dia determinado da semana em curso para realizá-las pode ser um bom começo para evitar correrias na semana final. E essas atividades deveriam ser agendadas em função do tempo de que se dispõe para trabalhar: se tenho mais tempo, posso resolver tarefas mais complexas, se tenho menos tempo ou só tenho algumas horas tarde de noite após ter trabalhado o dia todo, as ocuparei para a realização do trabalho "braçal", como passar o corretor ortográfico ou organizar a lista de referências bibliográficas. 
Tenha leitores voluntários

e seja também um

Os estudantes de graduação e pós-graduação deveriam começar combinando com a orientadora a planificar a pesquisa e sua escrita, incluindo apresentações em congressos, seminários internos, de versões parciais do trabalho. Mas é importante também conseguir leitores voluntários fora do circuito mais próximo de pesquisa, que podem ser seus colegas ou outros professores. Estabeleça, então, prazos com sua orientadora e com seus leitores voluntários para enviar os trabalhos, de maneira que eles abram espaço em suas agendas para ler e comentar, mas sobretudo, cumpra você mesmo os prazos e envie os textos na data prometida. Mesmo que o leitor voluntário seja seu melhor amigo ou seu colega de turma, o compromisso de ler o seu trabalho deve ser tratado com profissionalismo.

Nesse intercâmbio de dádivas, não fique apenas recebendo-as, mas veja também como devolver o favor, lendo e comentando o trabalho de seus colegas: você irá a aprender muito sobre o processo de escrita - próprio e alheio - revisando e corrigindo os trabalhos dos outros. Como já sabemos, para escrever, é fundamental ler.

\section{Reflexões finais}

Este artigo partiu da premissa que a escrita não é um processo simples nem linear e a publicação é um processo sistemático, coletivo e, em algum sentido, polifônico. Sem essa premissa (que supõe um autor que trabalha em diálogo com a comunidade acadêmica em geral e com os colegas da profissão no dia a dia) resulta impossível entender que a escrita não é o fruto do gênio individual inspirado, mas de um longo processo de escrita e reescrita, no qual outras mãos colaboram: pareceristas, editores, membros de comitês editoriais - quando não tradutores, revisores, diagramadores e copidesques.

Possivelmente você começou a ler este texto achando que encontraria uma receita simples para escrever e publicar. E depois de ter lido essas poucas páginas, você pode estar se sentindo um pouco desapontado: afinal, acaba de descobrir que há muito dever de casa a fazer antes de ver suas ideias finalmente publicadas. Se essa é sua sensação, estamos pois no bom caminho, no caminho de um potencial sucesso, como o de ver o seu artigo publicado. É preciso ler, escrever uma, três, dez vezes antes de ver um artigo em letras de forma. É preciso discutir, avaliar, resolver, editar, corrigir e recomeçar mais uma vez. E para tudo isso, é preciso fazer tempo: se organizar, abrir espaço na agenda, priorizar a escrita por sobre outras atividades. Como disse no início, a escrita não é uma atividade natural nem espontânea, nem mesmo 
para quem "trabalha de escrever", então não espere que a inspiração ou o tempo apareça por um passe de mágica. Mas a satisfação de ver sua ideia, aquela que pairava em sua cabeça e que tanto Ihe entusiasmava discutir, encontrar finalmente um público mais amplo e ganhar uma vida e um uso autônomo, vale realmente a pena o esforço e o tempo investido.

\section{Referências}

BECKER, Howard. Writing for social scientists: how to start and finish your thesis, book, or article. Chicago: University of Chicago Press, 1986.

BECKER, Lucinda; DENICOLO, Pam. Publishing journal articles. London: Sage, 2012. BELCHER, Wendy. Como escribir un artículo académico en 12 semanas. Guía para publicar con éxito. México: Flacso, 2010.

- Reflections on ten years of teaching writing for publication to graduate students and junior faculty. Journal of Scholarly Publishing, v. 40, n. 2, p. 184-200, 2009.

BOLKER, Joan. Writing your dissertation in fifteen minutes a day: a guide to starting, revising, and finishing your doctoral thesis. New York: Owl Books, 1998.

BOURDIEU, Pierre; CHAMBOREDON, Jean-Claude; PASSERON, Jean-Claude. El oficio de sociólogo. 11. ed. México: Siglo XXI, 1988.

BRANSON, Richard. Anatomy of a research paper. Respiratory Care, v. 49, n. 10, p. 1222-1228, 2004.

BURSZTYN, Marcel; DRUMMOND, José Augusto; PINHEIRO DO NASCIMENTO, Elimar. Como escrever (e publicar) um trabalho científico. Dicas para pesquisadores e jovens cientistas. Rio de Janeiro: Garamond, 2010.

CALCAGNO, V.; DEMOINET, E.; GOLLNER, K.; GUIDI, L.; RUTHS, D.; MAZANCOURT, C. Flows of research manuscripts among scientific journals reveal hidden submission patterns. Science, n. 338, p. 1065-1069, 2012.

CASSANY, Daniel. Describir el escribir. Cómo se aprende a escribir. Buenos Aires: Paidós Comunicación, 2011.

CORTÁZAR, Julio. Clases de literatura. Berkeley; Buenos Aires: Alfaguara, 2013 [1980]. 
GANS, J. S.; SHEPHERD, G. B. How are the mighty fallen: rejected classic articles by leading economists. Journal of Economic Perspective, v. 8, n. 1, p. 165-179, 1994.

GRAUERHOLZ, Liz. Creating and teaching writing intensive courses. Teaching Sociology, v. 27, p. 310-323, 1999.

HANAFI, Sari. University systems in the Arab East: Publish globally and perish locally vs publish locally and perish globally. Current Sociology, v. 59, n. 3, p. 291-309, 2011.

HARTLEYK, James. New ways of making academic articles easier to read. International Journal of Clinical and Health Psychology, v. 12, n. 1, p. 143-160, 2012.

JOHNSON, Brad; MULLEN, Carol. Write to the top: kow to become a prolific academic. New York: Palgrave, McMillan \& Digital Printing, 2007.

KNORR CETINA, Karim. La fabricación del conocimiento. Un ensayo sobre el carácter constructivista y contextual de la ciencia. Bernal: Universidad Nacional de Quilmes Editorial, 2005 [1981].

MARTín, Eloísa. How double-blind peer review works and what it takes to be a good referee. Current Sociology, v. 64, n. 5, p. 691-698, 2016a.

—. Publicação acadêmica internacional e o lugar do Brasil na sociologia global. In: COSTA PINHEIRO, C.; BUARQUE DE HOLANDA, B.; MAIA, J. (Orgs.). Ateliê do Pensamento Social Práticas e Textualidades. Pensando a pesquisa e a publicação em ciências sociais, p. 47-70. Rio de Janeiro: FGV, 2016b.

—. Letters of rejection. Current Sociology, v. 63, n. 7, p. 937-942, 2015.

—. How to write a good article. Current Sociology, v. 62, n. 7, p. 949-955, 2014.

SLAFER, Gustavo A. ¿Cómo escribir un artículo científico? Revista de Investigación en Educación, n. 6, p. 124-132, 2009.

SOLACI, Luciana; PEREIRA, Mauricio. The introduction, methods, results, and discussion (IMRaD) structure: a fifty-year survey. Journal of Medicine Library Association, v. 92, n. 3, p. 364-367, 2004.

SOMERS, Patricia. Gênero e outras variáveis que influenciam na procrastinação acadêmica. Educação, v. 31, n. 1, p. 54-60, Jan./Abr. 2008.

STRATHERN, Marilyn (Ed.). Anthropological studies in accountability, ethics and the academy. London; New York: Routledge, 2000. 
- "Improving ratings": audit in the British University system". European Review, v. 5, Issue 3, p. 305- 321, 1997.

VANDERSTRAETEN, Raf. Scientific communication: sociology journals and publication practices. Sociology, v. 44, n. 3, p. 559-576, 2010.

WALLACE, Mike; WRAY, Allison. Critical reading and writing for post graduates. 3. ed. London: Sage, 2016.

YORE, Larry; HAND, Brian; PRAIN, Vaughan. Scientists as writers. Science Education, n. 86, p. 672-692, 2002.

(c) (i) (8) 
